\title{
HUBUNGAN PENGETAHUAN DENGAN MINAT AKSEPTOR KB SUNTIK MENGGUNAKAN AKDR Di BPM Ny. Tipuk Riani di Desa Sumberkepuh Kecamatan Tanjunganom Kabupaten Nganjuk
}

Siti Komariyah ${ }^{1}$, Via Wulan Puspita ${ }^{2}$

Akademi Kebidanan Dharma Husada Kediri Jawa Timur

\begin{abstract}
ABSTRAK
AKDR adalah alat kontrasepsi dalam rahim. Efek samping AKDR jika tidak diketahui oleh akseptor KB suntik dengan benar maka kecenderungan drop out meningkat atau berkurangnya minat dalam penggunaan AKDR yang harus dapat diantisipasi secara dini.Tujuan penelitian ini adalah mengetahui hubungan pengetahuan dengan minat akseptor KB suntik menggunakan AKDR.

Penelitian ini menggunakan rancangan korelasional dengan pendekatan cross sectional. Populasi penelitian semua akseptor KB suntik yang periksa di BPM Ny. Tipuk Riani, dengan teknik accidental sampling diperoleh sampel sejumlah 53 responden. Variabel independentyaitu pengetahuan akseptor KB suntik tentang AKDR, variabel dependentyaitu minat akseptor KB suntik menggunakan AKDR.Instrumen penelitian menggunakan kuesioner. Lokasi penelitian diBPM Ny. Tipuk Riani desa Sumberkepuh kecamatan Tanjunganom kabupaten Nganjuk. Waktu penelitian 9 April 2016 - 2 Agustus 2016.Pengolahan data dengan cara editing, coding, scoring, tabulating. Data dianalisis menggunakan Spearman Rank.

Hasil penelitian didapatkan pengetahuan akseptor KB suntikberpengetahuan cukup tentang AKDR sebanyak26 (49,0\%) responden. Minat akseptor KB suntik memiliki minat tinggimenggunakan AKDR sebanyak46 $(86,7 \%)$ responden. Hasil uji statistik didapatkan $Z_{\text {hitung }}=3,40$ dan bila dibandingkan dengan $Z_{\text {tabel }} \alpha=0,05$ adalah 1,960 maka $Z_{\text {hitung }}>Z_{\text {tabelyaitu 3,40 }>}$ 1,960 .

$\mathrm{H}_{1}$ diterima artinya ada hubungan pengetahuan dengan minat Akseptor KB suntik menggunakan AKDR.Informasi tentang KB AKDR lebih di tingkatkan sehingga akseptor $\mathrm{KB}$ suntik mampu menentukan metode kontrasepsi terbaik yang akan digunakan.Pengetahuan yang cukup tentang AKDR akan menjadi dasarmeningkatnya minat menggunakan AKDR.
\end{abstract}

Kata Kunci : Pengetahuan, Akseptor KB Suntik, Minat, AKDR

Korespondensi: Wilis Indah Kediri Jawa Timur HP: 081334697967,email: sitikomariyah@,gmail.com 


\section{PENDAHULUAN}

Tingginya laju pertumbuhan yang tidak diiringi peningkatan kualitas penduduk ini terus dilakukan upaya penanganan yaitu dengan program Keluarga Berencana. Keluarga berencana adalah usaha untuk mengukur jumlah dan jarak anak yang diinginkan. Agar dapat mencapai hal tersebut, maka dibuatlah beberapa cara atau aternatif untuk mencegah ataupun menunda kehamilan. Cara cara tersebut termasuk kontrasepsi atau pencegahan kehamilan dan perencanaan keluarga. ( Sulistyawati, 2011:12)

Pemerintah terus berupaya untuk menekan laju pertumbuhan dengan program Keluarga Berencana (KB). Salah satu upaya yang dilakukan dalam mensukseskan program Keluarga Berencana tersebut adalah dengan memberikan pelayanan yang bermutu dan sesuai kebutuhan. (Handayari, 2010). Perencanaan keluarga menuju keluarga kecil bahagia dan sejahtera perlu dibuat dalam rangka menyelamatkan ibu dan anak akibat melahirkan pada usia muda, jarak kelahiran yang terlalu dekat, dan melahirkan pada usia tua. (Sulistyawati, 2011 : 135)

Metode kontrasepsi yang tersebar di Indonesia terdapat beberapa pilihan yaitu metode kontrasepsi sederhana (metode amenorea laktasi (MAL), metode Keluarga Berencana Alamiah (KBA), senggama terputus, metode barier, metode kontrasepsi hormonal (kontrasepsi kombinasi, kontrasepsi progestin), metode dengan alat kontrasepsi dalam rahim (AKDR), dan kontrasepsi mantap. Semua kontrasepsi tersebut mempunyai kekurangan dan kelebihan sendiri-sendiri.

Handayani, 2010 : 36)

AKDR (Alat Kontrasepsi Dalam Rahim) adalah suatu alat atau benda yang dimasukkan ke dalam rahim yang sangat efektif, reversibel, dan berjangka panjang, dapat dipakai oleh semua perempuan usia reproduktif . ( Handayani, 2010 : 139). AKDR merupakan metode kontrasepsi yang sangat efektif yaitu 0,6-0,8 kehamilan/100 perempuan dalam 1 tahun pertama (1 kegagalan dalam 125-170 kehamilan) dan berjangka panjang 10 tahun (Syaifudin, $2006: 75$ ).

AKDR memiliki keuntungan yaitu pemasangan tidak memerlukan medis teknis yang sulit, kontrol medis yang ringan, penyulit tidak terlalu berat, dan pulihnya kesuburan setelah AKDR dicabut berlangsung baik. Sedangkan kerugian dari memakai AKDR adalah masih dapat terjadi kehamilan dengan AKDR in situ, terdapat perdarahan, leukorea, dapat terjadi infeksi, tingkat akhir infeksi menimbulkan kemandulan, dan tali AKDR dapat menimbulkan perlukaan portio uteri dan mengganggu hubungan seksual. Hal ini perlu diketahui oleh perempuan sebagai pengetahuan tentang Kontrasepsi AKDR agar dapat menentukan alat kontrasepsi yang akan dipakainya. (Manuaba, 2010 : 611)

Sebenarnya banyak keunggulan metode kontrasepsi ini, namun begitu tidak semua klien berminat dikarenakan berbagai alasan yang berbeda-beda seperti takut efek samping, takut proses pemasangan, dilarang oleh suami karena takut benangnya mengganggu saat bersenggama dan kurangnya pengetahuan tentang KB AKDR. 
Akibat dari kurangnya pengetahuan akseptor tentang AKDR tersebut sebagian besar tidak berminat untuk menggunakan AKDR.

Sebagian besar masyarakat Indonesia yang menggunakan alat kontrasepsi memilih yang metode non kontrasepsi jangka panjang dikarenakan masyarakat Indonesia sebagian besar masih menginginkan punya anak lagi setelah menggunakan alat kontrasepsi, maka dari itu mereka memilih alat kontrasepsi jangka pendek agar ketika mereka memiliki keinginan untuk mempunyai anak lagi, efek dari alat kontrasepsi tersebut dapat segera hilang dan mereka dapat segera melakukan proses produksi untuk mendapat keturunan yang mereka inginkan. (Wordpress, 2010).

Secara Nasional, pada Agustus tahun 2015 sebanyak 4.142.186 peserta KB. Apabila dilihat per kontrasepsi maka presentasinya sebagai berikut : 2.135.259 peserta suntik $(51,55 \%), 21.038 .237$ peserta pil $(25,06 \%), 287.028$ peserta AKDR $(6,93 \%), 391.464$ peserta implant $(9,45 \%), 217.817$ peserta kondom $(5,26 \%), \quad 66.456$ peserta MOW $(1,60 \%), \quad 5.925$ peserta MOP $(0,14 \%)$. Mayoritas peserta KB didominasi oleh peserta $\mathrm{KB}$ yang menggunakan suntik dan pil, sedangkan pemakai AKDR berada di urutan ke tiga. (BKKBN 2015)

Karena rendahnya minat pemakaian AKDR, maka penyuluhan tentang keunggulan metode AKDR hendaknya lebih ditingkatkan mengingat banyak masyarakat yang pengetahuannya rendah atau kurang. Penyuluhan diharapkan melibatkan suami sehingga turut memberi dukungan kepada ibu dalam penggunaan metode AKDR. Perlu metode baru untuk menarik minat, serta informasi yang disampaikan agar mudah dimengerti oleh ibu, sehingga tujuan dari penyuluhan dapat tercapai sesuai dengan apa yang diharapkan.

\section{METODE}

Dalam penelitian ini menggunakan pendekatan Cross Sectional. Pada penelitian ini populasinya semua Akseptor KB suntik yang periksa di BPM Ny. Tipuk Riani di desa Sumberkepuh kecamatan Tanjunganom kabupaten Nganjuk. Pada penelitian ini sampel yang digunakan adalah sebagian akseptor KB suntik yang periksa di BPM Ny. Tipuk Riani di desa Sumberkepuh kecamatan Tanjunganom kabupaten Nganjuk yang berjumlah 53 responden.

Kriteria insklusi pada penelitian ini adalah :

1) Akseptor $\mathrm{KB}$ suntik yang pada saat dilakukan penelitian datang dan periksa di di BPM Ny. Tipuk Riani di desa Sumberkepuh kecamatan Tanjunganom kabupaten Nganjuk

2) Akseptor $\mathrm{KB}$ suntik yang bisa membaca dan menulis

3) Akseptor KB suntik yang bersedia menjadi responden

Kriteria eksklusi pada penelitian ini adalah :

1) Akseptor $\mathrm{KB} \mathrm{AKDR}$, pil, kondom, implant, MOP, MOW

2) Akseptor KB suntik yang mempunyai keluhan

Dalam penelitian ini dipilih teknik accidental sampling (sampling sesaat). Dalam penelitian ini, variabel bebas adalah pengetahuan akseptor KB suntik tentang AKDR. Dalam penelitian ini, variabel terikatnya adalah minat akseptor KB suntik menggunakan AKDR. 
HASIL

\section{Data Umum}

a. Karakteristik Responden Berdasarkan Umur Ibu

Tabel 1 : Karakteristik akseptor KB suntik Berdasarkan Umur (Tahun) di BPM Ny. Tipuk Riani di desa Sumberkepuh kecamatan Tanjunganom kabupaten Nganjuk

\begin{tabular}{cccc} 
No & Umur (Tahun) & Frekuensi & Prosentase $(\%)$ \\
\hline 1 & $20-25$ & 14 & 26,5 \\
\hline 2 & $26-30$ & 17 & 32,0 \\
\hline 3 & $31-35$ & 16 & 30,2 \\
\hline 4 & $>35$ & 6 & 11,3 \\
\hline \multicolumn{2}{r}{ Total } & 53 & 100
\end{tabular}

b. Karakteristik Responden Berdasarkan Pendidikan Ibu

Tabel 2 : Karakteristik akseptor KB suntik Berdasarkan Pendidikan di BPM Ny. Tipuk Riani di desa Sumberkepuh kecamatan Tanjunganom kabupaten Nganjuk

\begin{tabular}{clcc} 
No & Pendidikan Terakhir & Frekuensi & Prosentase $(\%)$ \\
\hline 1 & SD & 5 & 9,5 \\
\hline 2 & SMP/Sederajat & 15 & 28,3 \\
\hline 3 & SMA/Sederajat & 20 & 37,7 \\
\hline 4 & Diploma/Sarjana & 13 & 24,5 \\
\hline \multicolumn{2}{c}{ Total } & 53 & 100
\end{tabular}

c. Karakteristik Responden Berdasarkan Pekerjaan Ibu

Tabel 3 : Karakteristik Akseptor KB suntik Berdasarkan Pekerjaan di BPM Ny. Tipuk Riani di desa Sumberkepuh kecamatan Tanjunganom kabupaten Nganjuk

\begin{tabular}{clcc} 
No & \multicolumn{1}{c}{ Pekerjaan } & Frekuensi & Prosentase $(\%)$ \\
\hline 1 & Tidak bekerja (IRT) & 25 & 47,1 \\
\hline 2 & Petani & 7 & 13,2 \\
\hline 3 & PNS & 6 & 11,3 \\
\hline 4 & Swasta & 12 & 22,7 \\
\hline 5 & Wiraswasta & 3 & 5,7 \\
\hline & Total & 53 & 100
\end{tabular}

d. Karakteristik Responden Berdasarkan Penghasilan Ibu

Tabel 4 : Karakteristik Akseptor KB suntik Berdasarkan Penghasilan di BPM Ny. Tipuk Riani di desa Sumberkepuh kecamatan Tanjunganom kabupaten Nganjuk. 


\begin{tabular}{clcc} 
No & \multicolumn{1}{c}{ Penghasilan } & Frekuensi & Prosentase (\%) \\
\hline 1 & Tidak berpenghasilan & 25 & 47,1 \\
\hline 2 & $<$ Rp. 500.000 & 9 & 17,0 \\
\hline 3 & Rp. $500.000-1.000 .000$ & 10 & 18,9 \\
\hline 4 & Rp. $1.000 .000-1.500 .000$ & 2 & 3,8 \\
\hline 5 & $>$ Rp. 1.500 .000 & 7 & 13,2 \\
\hline & Total & 53 & 100
\end{tabular}

e. Karakteristik Responden Berdasarkan Jumlah Anak

Tabel 5 : Karakteristik Akseptor KB suntik Berdasarkan Jumlah Anak di BPM Ny. Tipuk Riani di desa Sumberkepuh kecamatan Tanjunganom kabupaten Nganjuk

\begin{tabular}{|c|l|c|c|}
\hline No & \multicolumn{1}{|c|}{ Jumlah Anak } & Frekuensi & Prosentase (\%) \\
\hline 1 & 1 anak & 24 & 45,3 \\
\hline 2 & $2-3$ anak & 26 & 49,0 \\
\hline \multicolumn{2}{|c|}{ 4 anak } & 3 & 5,7 \\
\hline \multicolumn{2}{|c|}{ Total } & 53 & 100 \\
\hline
\end{tabular}

f. Karakteristik Responden Berdasarkan Informasi KB AKDR

Tabel 6: Karakteristik Akseptor KB suntik Berdasarkan Informasi di BPM Ny. Tipuk Riani di desa Sumberkepuh kecamatan Tanjunganom kabupaten Nganjuk

\begin{tabular}{|c|c|c|c|}
\hline No & Informasi & Frekuensi & Presentasi (\%) \\
\hline 1 & Pernah & 53 & 100 \\
\hline 2 & Tidak & 0 & 0 \\
\hline & Total & 35 & 100 \\
\hline
\end{tabular}

g. Karakteristik Responden Berdasarkan Informasi yang diperoleh

Tabel 7 : Karakteristik Akseptor KB suntik Berdasarkan Sumber Informasi di BPM Ny. Tipuk Riani di desa Sumberkepuh kecamatan Tanjunganom kabupaten Nganjuk

\begin{tabular}{cccc} 
No & Sumber Informasi & Frekuensi & Prosentase $(\%)$ \\
\hline 1 & Televisi/Elektronik & 3 & 5,7 \\
\hline 2 & Media Cetak & 4 & 7,6 \\
\hline 3 & Bidan/Nakes & 42 & 79,2 \\
\hline 4 & Keluarga & 0 & 0 \\
\hline 5 & Orang Lain & 4 & 7,6 \\
\hline & Total & 53 & 100
\end{tabular}


a. Pengetahuan Akseptor KB suntik menggunakan AKDR

Tabel IV.8 : Pengetahuan Akseptor KB suntik di BPM Ny. Tipuk Riani di desa Sumberkepuh kecamatan Tanjunganom kabupaten Nganjuk

\begin{tabular}{ccccccccc}
\multirow{2}{*}{ No } & \multirow{2}{*}{ Indikator } & \multicolumn{7}{c}{ Pengetahuan } \\
\cline { 3 - 8 } & & \multicolumn{3}{c}{ Baik } & \multicolumn{2}{c}{ Cukup } & \multicolumn{2}{c}{ Kurang } \\
\cline { 2 - 8 } & & Jumlah & $\%$ & Jumlah & $\%$ & Jumlah & $\%$ \\
\hline 1 & Pengertian & 33 & 62,2 & 19 & 35,8 & 1 & 1,8 \\
\hline 2 & Keuntungan & 29 & 54,7 & 0 & 0 & 24 & 45,3 \\
\hline 3 & Kerugian & 8 & 15,1 & 34 & 64,1 & 11 & 20,8 \\
\hline 4 & Efek Samping & 26 & 49,1 & 0 & 0 & 27 & 50,9 \\
\hline 5 & Komplikasi & 24 & 45,2 & 24 & 45,2 & 5 & 9,5 \\
\hline \multirow{2}{*}{6} & Petunjuk & 28 & 52,8 & 18 & 33,9 & 7 & 13,2 \\
& Penggunaan & & & & & & \\
\hline 7 & Indikasi & 29 & 54,7 & 0 & 0 & 24 & 45,2 \\
\hline 8 & Kontra Indikasi & 22 & 41,5 & 0 & 0 & 31 & 58,4 \\
\hline \multirow{2}{*yyyyyyy}{} & Pengetahuan & $\mathbf{2 4}$ & $\mathbf{4 5 , 3}$ & $\mathbf{2 6}$ & $\mathbf{4 9 , 0}$ & $\mathbf{3}$ & $\mathbf{5 , 7}$
\end{tabular}

b. Minat Akseptor KB suntik di BPM Ny. Tipuk Riani di desa Sumberkepuh kecamatan Tanjunganom kabupaten Nganjuk

Tabel 9 : Minat Akseptor KB suntik di BPM Ny. Tipuk Riani di desa Sumberkepuh kecamatan Tanjunganom kabupaten Nganjuk

\begin{tabular}{ccccccccc}
\multirow{2}{*}{ No } & \multirow{6}{*}{ Indikator } & \multicolumn{2}{c}{ Minat } \\
\cline { 3 - 8 } & & \multicolumn{2}{c}{ Tinggi } & \multicolumn{2}{c}{ Sedang } & \multicolumn{2}{c}{ Rendah } \\
\cline { 3 - 8 } & & Jumlah & $\%$ & Jumlah & $\%$ & Jumlah & $\%$ \\
\hline 1 & Ketertarikan & 49 & 92,4 & 4 & 7,6 & 0 & 0 \\
\hline 2 & Perhatian & 46 & 86,7 & 7 & 13,3 & 0 & 0 \\
\hline 3 & Motivasi & 38 & 71,6 & 15 & 28,4 & 0 & 0 \\
\hline 4 & Pengetahuan & 48 & 90,5 & 5 & 9,5 & 0 & 0 \\
\hline & Minat & $\mathbf{4 6}$ & $\mathbf{8 6 , 7}$ & $\mathbf{7}$ & $\mathbf{1 3 , 3}$ & $\mathbf{0}$ & $\mathbf{0}$
\end{tabular}

c. Hubungan Pengetahuan dengan Minat Akseptor KB suntik menggunakan AKDR di BPM Ny. Tipuk Riani di desa Sumberkepuh kecamatan Tanjunganom kabupaten Nganjuk.

Tabel 10 : Hubungan Pengetahuan dengan Minat Akseptor KB suntik menggunakan AKDR di BPM Ny. Tipuk Riani di desa Sumberkepuh kecamatan Tanjunganom kabupaten Nganjuk

\begin{tabular}{lcccccccc}
\multirow{2}{*}{$\begin{array}{l}\text { Minat } \\
\text { Pengetahuan }\end{array}$} & \multicolumn{2}{c}{ Tinggi } & \multicolumn{2}{c}{ Sedang } & \multicolumn{2}{c}{ Rendah } & \multicolumn{2}{c}{ Jumlah } \\
\cline { 2 - 9 } & $\mathrm{N}$ & $\%$ & $\mathrm{~N}$ & $\%$ & $\mathrm{~N}$ & $\%$ & $\mathrm{~N}$ & $\%$ \\
\hline Baik & 23 & 43,3 & 1 & 1,9 & 0 & 0 & 24 & 45,3 \\
\hline Cukup & 22 & 41,5 & 4 & 7,6 & 0 & 0 & 26 & 49,0 \\
\hline Kurang & 1 & 1,9 & 2 & 3,8 & 0 & 0 & 3 & 5,7
\end{tabular}




\begin{tabular}{ccccccccc} 
Jumlah & $\mathbf{4 6}$ & $\mathbf{8 6 , 7}$ & $\mathbf{7}$ & $\mathbf{1 3 , 3}$ & $\mathbf{0}$ & $\mathbf{0}$ & $\mathbf{5 3}$ & $\mathbf{1 0 0}$ \\
\hline Spearman Rank $($ Rho $)$ & $\mathrm{Z}_{\text {Hitung }}=3,40$ & $\mathrm{Z}_{\text {tabel }}=1,960$ &
\end{tabular}

\section{DISKUSI}

\section{Pengetahuan Akseptor KB Suntik Menggunakan AKDR}

Berdasarkan hasil penelitian pada tabel 8 menunjukkan bahwa dari 53 responden yang diteliti didapatkan 24 responden $(45,3 \%)$ berpengetahuan baik, 26 responden (49\%) berpengetahuan cukup, 3 $(5,7 \%)$, berpengetahuan kurang.

Pengetahuan merupakan hasil "tahu" dan ini terjadi setelah orang mengadakan pengindraan terhadap suatu objek tertentu. Pengindraan terhadap suatu objek terjadi melalui panca indra manusia yakni penglihatan, pendengaran, penciuman, rasa dan raba dengan sendiri. Sebagian besar pengetahuan manusia diperoleh melalui mata dan telinga. Sehingga responden harus memiliki pengetahuan yang benar khususnya pengetahuan tentang AKDR. (Wawan \& Dewi, 2011 : 11).

Dari hasil penelitian diatas dapat dilihat bahwa sebagian besar responden di Ny. Tipuk Riani desa Sumberkepuh kecamatan Tanjunganom kabupaten Nganjuk mempunyai pengetahuan yang cukup tentang KB AKDR. Akseptor KB Suntik yang mempunyai pengetahuan cukup tentang KB AKDR berarti akseptor KB suntik tersebut memiliki wawasan yang cukup tentang jenis KB AKDR. Wawasan dan pengetahuan yang di miliki akseptor $\mathrm{KB}$ suntik tentang $\mathrm{KB}$ AKDR tersebut akan menjadi dasar responden untuk bersikap dan bertindak dalam kesehariannya untuk memilih $\mathrm{KB}$ mana yang akan digunakan untuk mencegah kehamilan selanjutnya.

Pengetahuan tidak dapat muncul dengan sendirinya, banyak hal yang dapat dilakukan untuk menambah pengetahuan. Faktor yang mempengaruhi pengetahuan seseorang salah satunya adalah pendidikan. Berdasarkan tabel 2 dapat diketahui bahwa dari 53 responden, sebagian besar pendidikan akseptor $\mathrm{KB}$ suntik adalah SMA/Sederajat yaitu 20 (37,7\%).

Pendidikan berarti bimbingan yang diberikan seseorang terhadap perkembangan orang lain yang menuju ke arah cita-cita tertentu yang menentukan manusia untuk berbuat dan mengisi kehidupan untuk mencapai keselamatan dan kebahagiaan. Menurut YB Mantra yang dikutip Notoadmojo (2003), pendidikan dapat mempengaruhi seseorang termasuk juga prilaku seseorang akan pola hidup terutama dalam memotivasi untuk sikap berperan serta dalam pembangunan kesehatan.

Dari data diatas dapat disimpulkan bahwa akseptor KB suntik yang berpendidikan SMA, diploma/sarjana akan memiliki pengetahuan yang lebih baik dibandingkan dengan yang memiliki pendidikan rendah. Dengan dasar pendidikan yang dimiliki tersebut akan menjadi dasar akseptor KB suntik untuk lebih mudah mencari dan memahami pengetahuan yang berhubungan dengan $\mathrm{KB}$ yang berkembang di Indonesia khususnya KB AKDR. Dengan 
demikian dapat disimpulkan bahwa makin tinggi pendidikan, maka seseorang akan lebih mudah menangkap informasi yang diberikan sehingga pengetahuan tentang AKDR semakin bertambah baik.

Selain pendidikan, pekerjaan juga mempengaruhi pengetahuan. Berdasarkan tabel 3 dapat diketahui bahwa dari 53 responden, sebagian besar 25 (47,1\%) adalah Ibu Rumah Tangga.

Menurut Thomas yang dikutip oleh Nursalam (2013), pekerjaan adalah keburukan yang harus dilakukan untuk menunjang kehidupan dan kehidupan keluarga. Pekerjaan bukanlah sumber kesenangan, tetapi lebih banyak merupakan cara mencari nafkah yang membosankan, berulang dan banyak tantangan.

Responden yang bekerja sebagai ibu rumah tangga akan memiliki banyak waktu luang dirumah. Sehingga dengan waktu luang tersebut, akseptor KB suntik dapat menambah pengetahuannya tentang KB AKDR baik dengan cara bertukar pengalaman dengan keluarganya atau dengan membaca majalah dan juga melalui media lainnya. Responden sebagai ibu rumah tangga memiliki banyak kesempatan untuk mengikuti kegiatan diluar rumah, berinteraksi dengan orang sekitar dan bertukar pengalaman terkait mencari pengetahuan yang lebih tentang AKDR dan menumbuhkan minatnya memakai AKDR.

Pengetahuan akseptor KB suntik juga dapat dipengaruhi oleh informasi dan sumber informasi. Hasil penelitian didapatkan 53 responden maka dapat diketahui bahwa seluruh reponden, 53 orang
(100\%) pernah mendapatkan informasi tentang AKDR. Selain itu didukung sebagian besar dari responden yaitu 42 orang $(79,2 \%)$ mendapat informasi dari Bidan/tenaga kesehatan.

Informasi adalah sesuatu yang dapat diketahui, namun ada pula yang menekankan informasi sebagai transfer pengetahuan. Selain itu informasi juga dapat didefinisikan sebagai suatu teknik untuk mengumpulkan, menyiapkan, menyimpan, memanipulasi, mengumumkan, menganalisis, dan menyebarkan informasi dengan tujuan tertentu (Budiman, 2014: 5).

Akseptor KB yang pernah mendapat informasi tentang $\mathrm{KB}$ AKDR akan mempunyai dasar pengetahuan dan wawasan yang baik. Dengan pengetahuan yang dimiliki oleh akseptor $\mathrm{KB}$ tersebut akan menjadi dasar pengetahuan dan wawasan yang dimilikinya. Selain itu informasi yang didapat dari tenaga kesehatan atau bidan dimana bidan adalah orang yang selalu dipercaya dalam bidang kesehatan yang akan menambah kepercayaan akseptor KB suntik tentang informasi kesehatan yang didapatnya.

2. Minat Akseptor KB Suntik menggunakan AKDR

Berdasarkan tabel 9 menunjukkan bahwa 53 responden yang diteliti sebagian besar didapatkan 48 responden $(86,7 \%)$ memiliki minat tinggi.

Minat merupakan salah satu fungsi hidup kejiwaan manusia, dan dapat diartikan sebagai aktivitas psikis yang meng andung usaha aktif dan berhubungan pelaksanaan suatu tujuan (Ahmadi, 2009 : 112). 
Untuk memperoleh minat, dukungan dari diri sendiri untuk mencari tahu tentang KB AKDR, sehingga responden akan tertarik dan minat untuk menggunakan KB AKDR.

Sebagian responden mempunyai minat tinggi dalam melakukan menggunakan AKDR hal ini disebabkan oleh cukup baiknya pengetahuan tentang AKDR, dan sebagaian responden berpendidikan menengah keatas yang juga turut menunjang cara berfikir dalam pemilihan alat kontrasepsi yang digunakan.

Berdasarkan kuisoner yang dibagikan pada responden disebutkan bahwa dari 53 responden, diperoleh hasil bahwa pada kuisoner tentang ketertarikan sebagian besar tinggi yaitu 49 responden $(92,4 \%)$.

Minat adalah rasa lebih suka dan rasa ketertarikan pada suatu hal atau aktivitas, tanpa ada yang menyuruh. Minat pada dasarnya adalah penerimaan akan suatu hubungan antara diri sendiri dengan sesuatu di luar diri. Semakin kuat atau dekat hubungan tersebut, semakin besar minatnya (Djaali, 2013 : 121).

Ketertarikan tinggi yang dimiliki responden dapat mempengaruhi minat dari akseptor KB suntik agar beralih menggunakan KB AKDR

Selain itu minat responden dalam menggunakan KB AKDR dapat dipengaruhi oleh umur. Berdasarkan tabel 1 dapat diketahui bahwa dari 53 responden, bahwa sebagian besar akseptor KB suntik berumur 26-30 tahun yaitu sebanyak 17 (32,0\%).

Usia adalah lamanya seseorang hidup dihitung dari tahun lahirnya sampai dengan ulangtahunnya yang terahkir. Usia merupakan konsep yang masih abstrak bahkan menimbulkan variasi dalam pengukuranya. Seseorang mungkin menghitung umur dengan tepat tahun kelahirannya, sementara yang lain menghitungnya dalam ukuran tahun saja (Zaluchu, 2008 : 109).

Umur sangat berhubungan dengan pengalaman dan tingkat kematangan. Seseorang yang sudah cukup umur memiliki pengalaman terhadap segala hal yang jauh lebih luas dibandingkan dengan seseorang yang belum cukup umur ataupun yang belum mendapat terlalu banyak mendapat informasi.

Dilihat dari usia responden yang sebagian besar termasuk usia reproduktif dan dibekali minat yang baik hal ini perlu diberikan pengarahan yang lebih lanjut tentang manfaat AKDR untuk pemilihan

kontrasepsi selanjutnya agar semakin baik pengetahuan dan minatnya maka akseptor KB suntik dapat beralih ke KB AKDR.

Minat juga dipengaruhi oleh jumlah anak. Sebagian besar jumlah anak akseptor KB suntik di BPM Ny. Tipuk Riani, adalah 2-3 anak sekitar 26 responden (49\%).

Pengalaman adalah guru yang baik, demikian bunyi pepatah. Pepatah ini mengandung maksud bahwa pengalaman merupakan sumber pengetahuan, atau pengalaman itu merupakan suatu cara untuk memperoleh kebenaran pengetahuan. Oleh sebab itu, pengalaman pribadipun dapat digunakan sebagai upaya memperoleh pengetahuan. (Notoatmodjo, 2011:13).

Pengalaman individu tidak bisa dihapus atau dilupakan begitu saja, pengalaman akan membentuk 
kebiasaan seseorang dalam kehidupannya. Pengalaman terbaik akan mengarahkan responden dalam memilih kontrasepsi yang tepat, karena dengan pengalaman yang baik seseorang lebih mudah dalam memutuskan jenis kontrasepsi yang akan dipilih.

Responden yang memiliki jumlah anak cukup 2-3 anak akan memiliki pengalaman pribadi dalam pemilihan kontrasepsi. Pengalaman tersebut dapat dijadikan keyakinan untuk menentukan KB mana yang akan dipakainya untuk merencanakan kehamilan berikutnya dengan pertimbangan keuntungan yang lebih besar.

Dari kuisoner yang dibagikan sebanyak 53 responden diperoleh hasil bahwa pada kuisoner tentang motivasi sebanyak 38 responden (71,6\%) memiliki motivasi tinggi.

Minat sebagai sumber motivasi yang akan mengarahkan seseorang pada apa yang akan meraka lakukan bila diberi kebebasan untuk memilihnya. Bila mereka melihat sesuatu itu mempunyai arti bagi dirinya, maka mereka akan tertarik terhadap sesuatu itu yang pada ahkirnya nanti akan menimbulkan kepuasan bagi dirinya sendiri (Hurlock, 2008 : 114).

Usaha untuk menimbulkan minat seseorang adalah perlu adanya dorongan dan motivasi terutama dari tenaga kesehatan yang diharapkan dapat berperan aktif dalam memberikan motivasi kepada responden untuk menggunakan KB AKDR.

3. Hubungan Pengetahuan dengan Minat Akseptor KB Suntik Menggunakan AKDR di BPM Ny. Tipuk Riani desa Sumberkepuh

\section{kecamatan} kabupaten Nganjuk

Berdasarkan tabel 10
menunjukkan dari 53 responden yang diteliti didapatkan 23 responden $(43,3 \%)$ mempunyai pengetahuan baik dengan minat tinggi, 22 responden $(41,5 \%)$ mempunyai pengetahuan cukup dengan minat tinggi, 1 responden $(1,9 \%)$ mempunyai pengetahuan kurang dengan minat tinggi, 1 responden $(1,9 \%)$ mempunyai pengetahuan baik dengan minat sedang, 4 responden $(7,6 \%)$ mempunyai pengetahuan cukup dengan minat sedang, 2 responden $(3,8 \%)$ mempunyai pengetahuan kurang dengan minat sedang. Dari hasil hasil tabulasi silang tersebut dapat disimpulkan bahwa sebagian besar responden yang diteliti mempunyai pengetahuan baik dengan minat tinggi dalam pengetahuan tentang $\mathrm{KB}$ AKDR dan minat menggunakan $\mathrm{KB}$ AKDR.

Hasil analisa menggunakan Spearman Rank diketahui bahwa $Z_{\text {hitung }}$ sebesar 3,40 dengan $\alpha=0,05$ dan $Z_{\text {tabel }} 1,960$ sehingga $Z_{\text {hitung }}>$ $Z_{\text {tabel }}(3,40>1,960)$ Maka dapat disimpulkan bahwa $\mathrm{H}_{1}$ diterima, artinya ada hubungan pengetahuan dengan minat Akseptor KB Suntik menggunakan AKDR.

Menurut Notoadmojo (2010) pengetahuan adalah hasil tahu dari manusia, yang sekedar menjawab pertanyaan "what" misalnya apa air, apa manusia, apa alam dan sebagainya.

Minat adalah rasa lebih suka dan rasa ketertarikan pada suatu hal atau aktivitas, tanpa ada yang menyuruh. Minat pada dasarnya adalah penerimaan akan suatu hubungan antara diri sendiri dengan 
sesuatu di luar diri. Semakin kuat atau dekat hubungan tersebut, semakin besar minatnya (Djaali, 2013 : 121).

Dari data diatas menunjukkan bahwa adanya korelasi antara pengetahuan dengan minat akseptor KB suntik melakukan menggunakan AKDR. Semakin tinggi pengetahuan responden tentang KB AKDR maka semakin tinggi minat ibu untuk menggunakan KB AKDR. Pengetahuan menjadi faktor yang sangat penting untuk terbentuknya tindakan seseorang termasuk kemandirian serta keinginan dalam menggunakan KB AKDR.

Pengetahuan yang didasari dengan pemahaman yang tepat dan benar akan mempenggaruhi tanggapan positif dari responden, khususnya dalam pemilihan alat kontrasepsi yang tepat. Responden yang memiliki pemahaman yang tepat tentang AKDR baik dari keuntungan maupun kerugian akan dapat menambah pengetahuan tentang $\mathrm{KB}$ AKDR, sehingga responden dapat menyikapi kejadian di masyarakat yang mengabaikan pentingnya pemilihan AKDR.

Berdasarkan tabel 1 dapat diketahui sebagian besar akseptor KB suntik berumur 26-30 tahun yaitu sebanyak $17(32,0 \%)$, dan berdasarkan tabel IV.3 dapat diketahui bahwa dari 53 responden, sebagian besar $25(47,1 \%)$ adalah Ibu Rumah Tangga.

oleh Nursalam (2013), pekerjaan adalah keburukan yang harus dilakukan untuk menunjang kehidupan dan kehidupan keluarga.

Responden yang bekerja sebagai ibu rumah tangga memiliki banyak waktu luang dirumah. Dilihat dari usia responden yang sebagian besar termasuk usia reproduktif dan dibekali minat yang baik Dengan waktu luang tersebut, akseptor KB suntik dapat menambah pengetahuannya tentang KB AKDR, ditunjang dengan usia reproduktif yang lebih banyak rasa keingintahuannya dalam mencoba hal yang baru diketahui, terutama hal yang menarik minat dan perhatiannya.

\section{SIMPULAN}

1. Pengetahuan akseptor KB suntik tentang AKDR di BPM Ny. Tipuk Riani di desa Sumberkepuh kecamatan Tanjunganom kabupaten Nganjuk didapatkan 26 responden $(49,0 \%)$ mempunyai pengetahuan cukup.

2. Minat akseptor KB suntik menggunakan AKDR di BPM Ny. Tipuk Riani di desa Sumberkepuh kecamatan Tanjunganom kabupaten Nganjuk didapatkan sebagian besar responden yaitu 46 responden $(86,7 \%)$ mempunyai minat tinggi.

3. Ada hubungan antara pengetahuan dengan minat akseptor KB Suntik menggunakan AKDR di BPM Ny. Tipuk Riani di desa Sumberkepuh kecamatan Tanjunganom kabupaten Nganjuk. Berdasarkan hasil perhitungan dengan menggunakan uji statistik Spearman Rank didapatkan Z hitung $>Z_{\text {tabel }}(3,40>1,960)$ 


\section{DAFTAR PUSTAKA}

Ahmadi, Abu. 2009. Psikologi Umum. Jakarta : PT. Rineka Cipta.

Arikunto, Suharsimi. 2013. Prosedur Penelitian Suatu Pendekatan Praktik. Jakarta: Rineka Cipta.

Budiman, Agus Riyanto., 2014. Kapita Selekta Kuesioner Pengetahuan Dan Sikap Dalam Penelitian Kesehatan. Jakarta: Salemba Medika.

Djaali. 2013. Psikologi Pendidikan. Jakarta : Bumi Aksara

Depdiknas. 2008. Kamus Besar Bahasa Indonesia. Jakarta : Balai Pustaka

Everett, Suzanne, 2007. Buku Saku Kontrasepsi dan Kesehatan Seksual Reproduktif, Ed.2. Jakarta : EGC

Handayani Sri, 2010. Buku Ajar Pelayanan Keluarga Berencana. Yogyakarta : Pustaka Rihama

Hidayat Alimul A., 2012. Riset Keperawatan Dan Tehnik Penulisan Ilmiah. Jakarta: Salemba Medika.

Husada Bakti. 2013. Buku Saku Pelayanan Kesehatan Ibu di Fasilitas Kesedahatn Dasar dan Rujukan. Jakarta : Kementerian Kesehatan Republik Indonesia

Kurniawati, Hanifah Mirzanie. 2009. Obgynacea. Yogyakarta : Tosca Entreprise

Mulyani Nina, 2013. Keluarga Berencana dan Alat Kontrasepsi. Yogyakarta : Nuha Medika

Manuaba, I., 2010. Ilmu Kebidanan, Penyakit Kandungan Dan KB Untuk Pendidikan Bidan, Ed. 2. Jakarta : EGC
Mubaro, Iqbal. 2011. Promosi Kesehatan untuk Kebidanan. Jakarta : Salemba Medika

Noviawati Dyah, 2011. Panduan Lengkap Pelayanan KB Terkini. Yogyakarta : Nuha Medika

Notoatmodjo Soekidjo. 2010. Metodologi Penelitian Kesehatan. Jakarta: Rineka Cipta.

Nursalam, 2011. Konsep Dan Penerapan Metodologi Penelitian Ilmu Keperawatan. Jakarta: Salemba Medika.

Riyanto, Agus. 2014. Pengetahuan dan Sikap dalam Penelitian Kesehatan. Jakarta : Salemba Medika.

Proverawati, Atikah, 2010. Panduan Memilih Kontrasepsi. Yogyakarta : Nuha Medika

Saifuddin, Abdul B., 2006. Buku Panduan Praktis Pelayanan Kontrasepsi. Jakarta : Bina Pustaka

Saifuddin, Abdul B., 2011. Buku Panduan Praktis Pelayanan Kontrasepsi. Jakarta : Bina Pustaka

Sulistyawati Ari, 2011. Pelayanan Keluarga Berencana. Jakarta : Salemba Medika

Setiadi., 2007. Konsep Dan Penelitian Riset Keperawatan. Yogyakarta: Graha Ilmu.

Sugiono., 2012, Statistik Untuk Penelitian. Bandung: Alfabet.

Suharsimi, Arikunto. 2006. Prosedur Penelitian Suatu Pendekatan Praktik. Jakarta : PT. Rineka Cipta.

Sujarweni. 2014. Metode Penelitian. Yogyakarta : Pustaka Baru Pres 
Uliyah Mar'atul., 2010. Panduan Aman dan Sehat Memilih Alat KB. Yogyakarta : Pustaka Insan Madani

Wawan Dan Dewi., 2010. Teori Dan Pengukuran Pengetahuan, Sikap, Dan Prilaku Manusia. Yogyakarta:Nuha Medika.

Badan Kependudukan dan Keluarga Berencana Nasional, 2015. Laporan Hasil Pelayanan Kontrasepsi Agustus 2015 . Diakses dari : http://www.bkkbn.go.id/data/Default. aspx [25 April 2016]

Kamus Besar Bahasa Indonesia, 2008. Minat. [Online] (Update 2015). Diakses http://kbbi.web.id/minat. [13 April 2016].

Suparyanto, 2011. Konsep Dasar Minat. Diakses dari : $\mathrm{http}: / / \mathrm{dr}-$ suparyanto.blogspot.co.id/2011/01/ko nsep-dasar-minat.html?m=1 [28 April 2016]

Wikipedia, 2014. Keluarga Berencana. [Online] (Update 2014). Diakses dari : http://id.m.wikipedia.org/wiki/Ibu. [12 April 2016].

Wordpress, 2010. Konsep Minat. [Online] (Update, 18 Maret 2010). Diakses dari

https://creasoft.wordpress.com/2010/ 03/18/konsep-minat/.[27 April 2016] 